\title{
Scientific research clears Covid-19 mystery
}

\author{
Doaa A. Ghareeb \\ Department of Biochemistry, Faculty of Science, Alexandria University, Alexandria, Egypt \\ Pharmaceutical and Fermentation Industries Development Centre (PFIDC), City of Scientific Research and Technological \\ Applications (SRTA-City), Borg Al-Arab, Alexandria, Egypt
}

\section{IIII}

An outbreak of potentially lethal severe acute respiratory syndrome coronavirus 2 (SARS-CoV-2) or Covid-19 that appeared in last quarter 2019 leads to 574,475 death and $13,202,432$ cases till 13/7/2020. Since its appearance, all scientist worldwide had hardly worked to understand the virus structure, molecular mechanism, immune response, diagnosis, and potential investigational therapeutics. Till 13 July 2020, about 41754 scientific paper and reviews according to World Health Organization were published in different subjects' area consider Covid-19. Several studies were conducted to study the relation of environmental factor such as pollution, temperature, and humidity with the pattern of virus infection rate but there is no clear correlation between transmission pattern and environmental factors changes. The reported viral-transmission routs are close contact and aerosol therefore the primary infection organ is lung, but the virus can infect also digestive tract, kidney, and immune cells. Several blood parameters alterations such as lymphopenia, thrombocytopenia, leukopenia with low ferritin, $C D 4+T$ and $C D 8+T$ lymphocytes and high level of C-reactive protein (CRP), lactate dehydrogenase (LDH) and creatinine kinase (CK) higher-levels of IL- 6 and IL-10, and D-dimer are observed in Covid-19 patients.

Coronavirus has nucleocapsid, envelope, membrane, and spike structural proteins and RNA-dependent RNA polymerase (RdRp), coronavirus main protease (3chymotrypsin-like protease, $\left.3 \mathrm{CL}^{\text {pro }}\right)$, and papain-like protease $\left(\mathrm{PL}^{\text {pro }}\right)$ non-structural proteins. Spike protein binding domain has high affinity to angiotensin-converting enzyme 2 (ACE2) but it can binds with other receptor find in liver and dendritic cells which named sinusoidal endothelial cell C-type lectin (LSECtin), that co-expressed with dendritic cell-specific intercellular adhesion molecule-3 grabbing non-integrin (DC-SIGN).

Due to the current global emergency and the length of time required to develop specific antiviral agent(s) and a vaccine for SARS-CoV-2, WHO adopted the strategy of repurposing existing medications such as anti-inflammatory agents, immunosuppressant or antineoplastic agents, selective estrogen receptor modulators, antiviral drugs, and anti-malaria agents to treat COVID-19.

Chloroquine and hydroxychloroquine attach sialic acid's gangliosides in a way that prevents the viral $\mathrm{S}$ protein from binding to the gangliosides but these drugs have serious adverse effects, such as abdominal pain, nausea, vomiting, dyspepsia, rashes, and nightmares.

Camostat, umifenovir, lopinavir, ritonavir, pleconaril, and favipiravir which are potent antiviral used in many clinical studies as anti-covid 19 compounds because they inhibit $3 C^{\text {pro }}$ or RdRp. Anti-inflammatory drugs such as Indomethacin Tocilizumab, and JAK inhibitors used to prevent cytokines storm that play a center role in virus replication cycle. Beside that several vitamin and mineral can be used to prevent virus invasion and replication such as vitamin $C$ and zinc.

\section{IIII ARTICLE INFO}

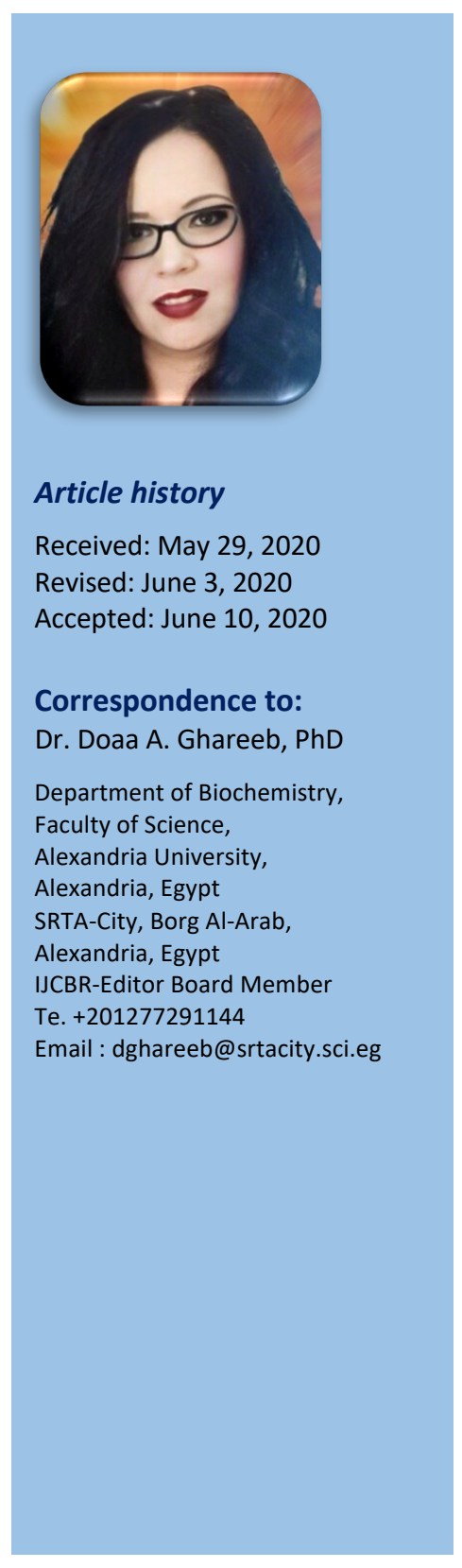

